\title{
Patient-centered medical home care access among adults with chronic conditions: National Estimates from the medical expenditure panel survey
}

\author{
Ziyad S Almalki ${ }^{*}$ D, Nedaa A Karami ${ }^{2}$, Imtinan A Almsoudi ${ }^{2}$, Roaa K Alhasoun ${ }^{3}$, Alaa T Mahdi ${ }^{4}$, Entesar A Alabsi ${ }^{5}$, \\ Saad M Alshahrani ${ }^{6}$, Nourah D Alkhdhran ${ }^{7}$ and Tahani M Alotaib ${ }^{7}$
}

\begin{abstract}
Background: The Patient-Centered Medical Home (PCMH) model is a coordinated-care model that has served as a means to improve several chronic disease outcomes and reduce management costs. However, access to PCMH has not been explored among adults suffering from chronic conditions in the United States. Therefore, the aim of this study was to describe the changes in receiving PCMH among adults suffering from chronic conditions that occurred from 2010 through 2015 and to identify predisposing, enabling, and need factors associated with receiving a PCMH.

Methods: A cross-sectional analysis was conducted for adults with chronic conditions, using data from the 2010-2015 Medical Expenditure Panel Surveys (MEPS). Most common chronic conditions in the United States were identified by using the most recent data published by the Agency for Healthcare Research and Quality (AHRQ). The definition established by the AHRQ was used as the basis to determine whether respondents had access to PCMH. Multivariate logistic regression analyses were conducted to detect the association between the different variables and access to PCMH care.

Results: A total of 20,403 patients with chronic conditions were identified, representing 213.7 million U.S. lives. Approximately $19.7 \%$ of the patients were categorized as the PCMH group at baseline who met all the PCMH criteria defined in this paper. Overall, the percentage of adults with chronic conditions who received a PCMH decreased from $22.3 \%$ in 2010 to $17.8 \%$ in 2015 . The multivariate analyses revealed that several subgroups, including individuals aged 66 and older, separated, insured by public insurance or uninsured, from low-income families, residing in the South or the West, and with poor health, were less likely to have access to PCMH.

Conclusion: Our findings showed strong insufficiencies in access to a PCMH between 2010 and 2015, potentially driven by many factors. Thus, more resources and efforts need to be devoted to reducing the barriers to PCMH care which may improve the overall health of Americans with chronic conditions.
\end{abstract}

Keywords: PCMH, MEPS, Care access, Chronic conditions

\footnotetext{
* Correspondence: z.almalki@psau.edu.sa

'Department of Clinical Pharmacy, College of Pharmacy, Prince Sattam Bin

Abdulaziz University, Al-Kharj, Riyadh, Saudi Arabia

Full list of author information is available at the end of the article
}

(c) The Author(s). 2018 Open Access This article is distributed under the terms of the Creative Commons Attribution 4.0 International License (http://creativecommons.org/licenses/by/4.0/), which permits unrestricted use, distribution, and reproduction in any medium, provided you give appropriate credit to the original author(s) and the source, provide a link to the Creative Commons license, and indicate if changes were made. The Creative Commons Public Domain Dedication waiver (http://creativecommons.org/publicdomain/zero/1.0/) applies to the data made available in this article, unless otherwise stated. 


\section{Background}

In the United States (U.S.), chronic conditions are among major causes of disability, mortality, and high medical costs [1-4]. It has been estimated that nearly half $(50.9 \%)$ of U.S. adults live with at least one chronic condition, while $26 \%$ have two or more chronic conditions [5]. These conditions are responsible for $46 \%$ of all deaths among the U.S. population annually. Furthermore, the associated costs of these conditions are enormous and compromise the health of the U.S. [6] It was estimated that $86 \%$ of U.S. health care expenditures are correlated with the treatment of chronic conditions [7].

With the growing number of chronic conditions [8], the associated costs made by these conditions will continue to threaten the entire federal budget. Over the last three decades, several improvements have been implemented into U.S. law, but they all focused heavily on insurance reforms. These steps will not be adequate unless they are coupled with fundamental health care improvement efforts targeting the primary care practice [9]. To achieve this goal, more attention has been paid to replace the poorly coordinated, acute-focused, episodic primary care practice with a care that is continuous, comprehensive, patient-centered, coordinated, and accessible, and that provides communication and shared decision-making [10].

A recent, successful approach to improve the chronic care management is the patient-centered medical home $(\mathrm{PCMH})$. The PCMH model is an innovative primary care delivery system that has served to improve the quality of care and to reduce medical costs. PCMH rearranges how primary care service is designed and delivered to the patients, with the prime focus on patient needs and preferences [11, 12]. Over the past few years, with the growing numbers of adults with chronic conditions, many healthcare stakeholders in the U.S. have adopted the PCMH to prevent or inhibit the progression of specific chronic conditions [12].

Several studies have demonstrated the ability of $\mathrm{PCMH}$ application in improving the primary care quality, safety, and efficiency across the U.S. Some studies, for example, have suggested that receiving $\mathrm{PCMH}$ care is associated with a decreased number of hospitalizations and emergency room visits [13-18]. Others have also identified improvements in the quality of health care after implementing $\mathrm{PCMH}$ care $[17,19,20]$.

Despite growing evidence in the literature that supports the effectiveness of the $\mathrm{PCMH}$ in improving health care outcomes and reducing costs, the extent of the PCMH's adoption in treating Americans with chronic conditions remains unknown. Therefore, the objective of this study is to describe, at the national level, the changes in receiving $\mathrm{PCMH}$ among adults suffering from chronic conditions and to identify predisposing, enabling, and need factors associated with accessing PCMH care.

\section{Methods}

\section{Data source}

We conducted an observational cross-sectional analysis of the 2010-2015 Medical Expenditure Panel Survey (MEPS). MEPS has been conducted by the Agency for Healthcare Research and Quality (AHRQ) since 1996. MEPS is a nationally representative population-based survey of health care utilization and expenditures of the U.S. civilian noninstitutionalized population. The MEPS utilizes an overlapping panel design in which participant data are collected over a series of five rounds of interviews spaced about five months apart. The collected data include patient demographics, access to health care, use of health services, health conditions, health status, and other data as well. Information regarding the data and a description of its survey design have been published previously [21].

\section{Study population}

Individuals aged 18 years and older who were diagnosed with at least one of the most common chronic conditions (i.e., hypertension, hyperlipidemia, mood disorders, diabetes, anxiety disorders, upper respiratory conditions, arthritis, asthma, or coronary artery disease) were identified. These conditions were considered to be chronic because they are long-lasting, cause diminished physical and/or mental capacity, or require long-term monitoring and medical interventions [22]. The prevalence of these conditions has been confirmed by the most recent data published by the Agency for Healthcare Research and Quality (AHRQ) [23]. According to MEPS documentation, patients in each year may be used as independent observations since each year in MEPS data is intended to be nationally representative [24].

\section{Primary outcome}

The primary outcome of our analysis was determining whether the individual was receiving care consistent with $\mathrm{PCMH}$ principles. PCMH care was defined using the provider-related questionnaires in MEPS. AHRQ's definition classifying PCMH care was used to determine whether respondents had a $\mathrm{PCMH}$ [25]. The respondent was considered to be receiving $\mathrm{PCMH}$ if the patient received comprehensive, patient-centered, and accessible care. Table 1 
Table 1 MEPS survey items used to define PCMH care

\begin{tabular}{|c|c|}
\hline PCMH criteria & Survey items used \\
\hline \multicolumn{2}{|c|}{ Comprehensive care } \\
\hline & $\begin{array}{l}\text { Does the provider usually ask about medications and } \\
\text { treatments prescribed by other doctors }\end{array}$ \\
\hline & Does the provider provide care for new health problems \\
\hline & Does the provider provide preventive healthcare \\
\hline & $\begin{array}{l}\text { Does the provider provide referrals to other health } \\
\text { professionals }\end{array}$ \\
\hline & $\begin{array}{l}\text { Does the provider provide care for ongoing health } \\
\text { problems }\end{array}$ \\
\hline
\end{tabular}

Does the provider show respect for the medical, traditional, and alternative treatments other doctors may give

Does the provider explain all healthcare options to participant

Does the provider ask participant to help decide treatment choice

Accessible care

Is it difficult to contact the provider by phone about a health problem during regular office hours

Does the provider offer night and weekend office hours

Does the provider speak the participant's language or provide translation services

shows the survey items used to define PCMH features based on AHRQ's criteria. Similar questions had been used in high-quality research to detect access to PCMH care using the same data [26-29].

We determined that the care received by an individual was comprehensive care if the provider did all of the following: 1) usually asked about any medications prescribed by other doctors; 2) provided care for new health problems; 3) provided preventive care; 4) offered referrals to other health professionals; and 5) provided care for ongoing health problems. We considered the individual to have received patient-centered care if the provider 1) showed respect for the medical, traditional, and alternative treatments other doctors may give; 2) explained all healthcare options to the individual; and 3) asked the individual to help decide on treatment. We considered care to be accessible if the provider 1) was easy to contact by phone about a health problem during regular office hours; 2) offered night and weekend office hours; and 3) spoke the participant's language or provided translation services. Participants with responses of don't know, refused, or not ascertained to any question were excluded from the final dataset.

\section{Independent variables}

By using the Andersen Behavioral Model [30] in the current analysis, we examined the effects of person- specific predisposing, enabling, and need factors on having a PCMH. Predisposing factors investigated in this study included age, sex, race, marital status, and education years. Enabling factors consisted of health insurance, employment status, family income, and census region. (Appendix A contains a list of states composing each region with demographic data.) [31] Our assessments of health needs were based on self-rated health status variables (good/excellent or poor/fair).

\section{Data analysis}

Descriptive statistics were used to characterize and evaluate changes in annual percentage for individuals who had PCMH over the six-year pooled dataset. The number of those individuals and their weighted percentage were calculated. Rao-Scott chi-square (a design-adjusted Pearson chi-square test) [32] analyses were performed to examine significant subgroup differences across strata for the two groups (having $\mathrm{PCMH}$ and having no $\mathrm{PCMH}$ ). Adjusted multiple logistic regression analyses were then conducted to assess predictors associated with having a PCMH. In all analyses, we control for age, sex, race, marital status, education years, health insurance type, employment status, family income, chronic conditions, and calendar year. The c-statistic was calculated for each model to assess the model's practical ability for correctly discriminating an individual outcome $(\mathrm{PCMH} / \mathrm{No}$ $\mathrm{PCMH}$ ). A model demonstrates a good discrimination when the c-statistic is $>0.7$ and outstanding when $>0.9$.

To adjust for the complex multistage survey design and nonresponse, the estimates that are calculated from the data sample were multiplied by person-specific sampling weights provided within the original datasets of MEPS. All analyses were conducted with the use of SAS 9.4 software (SAS, Cary, NC).

\section{Results}

A total of 20,403 patients with chronic conditions were identified, representing 213.7 million U.S. lives between 2010 and 2015. Approximately 19.7\% of the patients were categorized as the $\mathrm{PCMH}$ group at baseline who met all the PCMH criteria defined in this study. The proportion of adults with chronic conditions who received a PCMH decreased from $22.3 \%$ in 2010 to $17.8 \%$ in 2015 . However, in 2012 there was an increase in the number to $23.31 \%$ (Table 2).

Table 3 presents the results of the study population's descriptive characteristics. Individuals aged between 41 and 65 were most likely to report that they had at least one chronic condition (49.5\%). The overall sample was predominantly female $(57.1 \%)$, white $(79.5 \%)$, married 
Table 2 Annual changes in individuals with chronic conditions ${ }^{a}$

\begin{tabular}{lllll}
\hline Year & $N$ & N, weighted, in million & No PCMH, \% (95\% Cl) & $P C M H, \%(95 \% \mathrm{Cl})$ \\
\hline 2010 & 1458 & 15.6 & $77.69(74.73-80.64)$ & $22.31(19.35-25.26)$ \\
2011 & 2935 & 31.8 & $81.21(78.91-83.51)$ & $18.78(16.48-21.26)$ \\
2012 & 3725 & 37.3 & $76.68(74.42-78.94)$ & $23.31(21.05-25.57)$ \\
2013 & 33.7 & $81.31(79.05-83.57)$ & $18.68(16.42-20.94)$ \\
2014 & 3313 & 33.7 & $80.13(77.91-82.35)$ & $19.86(17.64-22.08)$ \\
2015 & 3112 & 61.3 & $82.17(80.37-83.97)$ & $17.82(16.02-19.62)$ \\
\hline
\end{tabular}

Abbreviations: $\mathrm{Cl}$, confidence interval

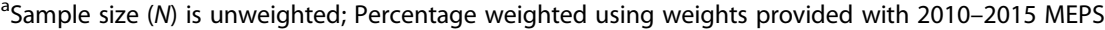

(57.8\%), educated beyond high school (59.6\%), insured by private insurance $(70.1 \%)$, employed $(58.1 \%)$, from a family with a high level of income $(42.1 \%)$, from the southern U.S. geographical region (38.2\%), and in excellent/good perceived health (79.7\%). Hypertension, arthritis, and hyperlipidemia were the most prevalent chronic conditions among the study sample, 47.4\%, $44.9 \%$, and $37.8 \%$, respectively.

Compared to those who did not receive a $\mathrm{PCMH}$, those who received $\mathrm{PCMH}$ were more likely to be younger, male individuals $(44.7 \%$ vs. $42.4 \%)$, married individuals $(62.1 \%$ vs. 56.7\%), employed $(62.7 \%$ vs. $57.01 \%$ ), from families with higher income levels (47.6\% vs. $40.8 \%)$, covered by private insurance $(76.6 \%$ vs. $68.5 \%)$, and in excellent/good perceived health status $(85.03 \%$ vs. $78.4 \%)$. They were also more likely to have achieved a higher level of education (had more than 12 years of education, $62.6 \%$ vs. $58.9 \%$ ), and less likely to be from the southern U.S. geographical region (31.8\% vs. $39.8 \%)$.

In Table 4, we found that the odds ratios (ORs) for individuals 66 years and older of having access to PCMH were 0.8 (confidence interval [CI]: 0.67-0.95). Compared with married individuals, those who were separated had significantly lower odds of having access to $\mathrm{PCMH}(O R=0.78 ; \mathrm{CI}: 0.67-0.91)$. Compared with individuals who completed fewer than 12 years of education, those who had more than 12 years of education had significantly higher odds of having a PCMH $(O R=1.25 ; \mathrm{CI}: 1.05-1.48)$.

The result shows that the most important driver of having a PCMH was health insurance status. Compared with individuals covered by private insurance, those with public insurance were $71 \%$ as likely to have access to $\mathrm{PCMH}$, while the uninsured were $73 \%$ as likely to have access to PCMH. There was also a significant difference in the employment status. Unemployed individuals were less likely to have access to $\mathrm{PCMH}$ compared to employed individuals $(O R=$ 0.83; CI: 0.74-0.93).

Significant differences in the family income were observed in relation to having $\mathrm{PCMH}$ access.
Individuals who were living in a poor or low-income family were about $33 \%$ less likely to have a $\mathrm{PCMH}$ compared to those living with a family with a high income $(O R=0.67 ; \mathrm{CI}: 0.57-0.78)$. Individuals living in the South and West were the most likely to not have access to PCMH compared to individuals living in the Midwest (South: $O R=$ 0.64; CI: 0.52-0.78; West: $O R=0.76$; CI: 0.61-0.96). The analyses also showed that individuals who reported having fair or poor health were negatively associated with having a PCMH compared to those who reported excellent or good general health (OR $=0.65$; CI: 0.57-0.76). In this population, individuals with the chronic conditions hyperlipidemia, mood disorders, anxiety disorders, and arthritis were significantly associated with limited access to PCMH. However, individuals diagnosed with upper respiratory conditions were positively associated with having access to a PCMH. The c-statistics associated with these adjusted logistic models ranged between 0.71 and 0.86 .

\section{Discussion}

As the first national study to present the extent of access to $\mathrm{PCMH}$ among adults with chronic conditions and to identify potential drivers for its trends, this study attempts to address this gap in the literature. In this research, we examined the prevalence of adult patients with chronic conditions who accessed $\mathrm{PCMH}$ care over the six-year period in the U.S.

This study found only a small percentage of patients with chronic conditions had access to $\mathrm{PCMH}$ care with a decreasing trend during the study period. This may raise concerns as this vulnerable population typically requires comprehensive and continuous care by primary care providers to manage their chronic physical problems, especially when the number and complexity of care needs increase as the number of chronic conditions a patient has increases [33]. In terms of medical services, the average numbers of 
Table 3 Baseline characteristics of individuals with chronic conditions, by PCMH access

\begin{tabular}{|c|c|c|c|c|c|c|c|}
\hline \multirow[t]{4}{*}{ Characteristic } & \multirow{4}{*}{$\begin{array}{l}\text { Total } \\
N \\
(N=20,403 ; \\
\text { Weighted } \\
N=213,733,954)\end{array}$} & \multirow{4}{*}{ Weighted \% } & \multicolumn{4}{|l|}{ Has a PCMH } & \multirow[t]{4}{*}{ P } \\
\hline & & & \multicolumn{2}{|l|}{ No } & \multicolumn{2}{|l|}{ Yes } & \\
\hline & & & $N$ & Weighted \% & $\bar{N}$ & Weighted \% & \\
\hline & & & $\begin{array}{l}(N=16,443 \\
\text { Weighted } \\
N=171,600,510)\end{array}$ & & $\begin{array}{l}(N=3960 \\
\text { Weighted } \\
N=42,133,444)\end{array}$ & & \\
\hline \multicolumn{8}{|l|}{ Predisposing } \\
\hline Age (Years) & & & & & & & 0.001 \\
\hline 19 to 40 & 5423 & 26.3 & 4299 & 25.9 & 1124 & 28.3 & \\
\hline 41 to 65 & 10,227 & 49.5 & 8213 & 49.2 & 2014 & 50.5 & \\
\hline 66 and older & 4753 & 24.1 & 3931 & 24.8 & 822 & 21.2 & \\
\hline Sex & & & & & & & 0.012 \\
\hline Female & 12,196 & 57.1 & 9926 & 57.6 & 2270 & 55.2 & \\
\hline Male & 8207 & 42.8 & 6517 & 42.4 & 1690 & 44.7 & \\
\hline Race & & & & & & & 0.8 \\
\hline Non-white & 6834 & 20.4 & 5485 & 20.5 & 1349 & 20.3 & \\
\hline White & 13,569 & 79.5 & 10,958 & 79.5 & 2611 & 79.6 & \\
\hline Marital Status & & & & & & & $<.0001$ \\
\hline Married & 10,810 & 57.8 & 8508 & 56.7 & 2302 & 62.1 & \\
\hline Never Married & 4272 & 18.4 & 3465 & 18.5 & 807 & 18.3 & \\
\hline Separated & 5321 & 23.6 & 4470 & 24.7 & 851 & 19.5 & \\
\hline Education Years & & & & & & & 0.001 \\
\hline$<12$ Years & 3505 & 14.1 & 2980 & 14.7 & 525 & 11.8 & \\
\hline 12 Years & 4764 & 26.2 & 3833 & 26.3 & 931 & 25.5 & \\
\hline$>12$ Years & 8876 & 59.6 & 6956 & 58.9 & 1920 & 62.6 & \\
\hline \multicolumn{8}{|l|}{ Enabling } \\
\hline Health Insurance & & & & & & & $<.0001$ \\
\hline Any Private & 12,422 & 70.1 & 9708 & 68.5 & 2714 & 76.6 & \\
\hline Public Only & 6301 & 23.7 & 5319 & 25.04 & 982 & 18.2 & \\
\hline Uninsured & 1680 & 6.2 & 1416 & 6.4 & 264 & 5.2 & \\
\hline Employment Status & & & & & & & $<.0001$ \\
\hline Employed & 11,006 & 58.1 & 8656 & 57.01 & 2350 & 62.7 & \\
\hline Not employed & 9336 & 41.8 & 7734 & 42.9 & 1602 & 37.2 & \\
\hline Family Income Categorical & & & & & & & $<.0001$ \\
\hline High & 6515 & 42.2 & 5001 & 40.8 & 1514 & 47.6 & \\
\hline Middle & 5913 & 28.4 & 4747 & 28.3 & 1166 & 28.8 & \\
\hline Poor/ Low & 7975 & 29.4 & 6695 & 30.8 & 1280 & 23.6 & \\
\hline Census Region & & & & & & & $<.0001$ \\
\hline Midwest & 4073 & 21.8 & 3175 & 20.9 & 898 & 25.5 & \\
\hline Northeast & 3355 & 17.8 & 2538 & 16.7 & 817 & 21.9 & \\
\hline South & 7872 & 38.2 & 6583 & 39.8 & 1289 & 31.8 & \\
\hline West & 5103 & 22.2 & 4147 & 22.5 & 956 & 20.8 & \\
\hline \multicolumn{8}{|l|}{ Healthcare Need } \\
\hline Self-Reported Health & & & & & & & $<.0001$ \\
\hline Excellent/Good & 15,144 & 79.7 & 1,1957 & 78.4 & 3187 & 85.03 & \\
\hline
\end{tabular}


Table 3 Baseline characteristics of individuals with chronic conditions, by PCMH access (Continued)

\begin{tabular}{|c|c|c|c|c|c|c|c|}
\hline \multirow[t]{4}{*}{ Characteristic } & \multirow{4}{*}{$\begin{array}{l}\text { Total } \\
N \\
(N=20,403 ; \\
\text { Weighted } \\
N=213,733,954)\end{array}$} & \multirow{4}{*}{ Weighted \% } & \multicolumn{4}{|l|}{ Has a PCMH } & \multirow[t]{4}{*}{$P$} \\
\hline & & & \multicolumn{2}{|l|}{$\overline{\text { No }}$} & \multicolumn{2}{|l|}{ Yes } & \\
\hline & & & $N$ & Weighted \% & $N$ & Weighted \% & \\
\hline & & & $\begin{array}{l}(N=16,443 \\
\text { Weighted } \\
N=171,600,510)\end{array}$ & & $\begin{array}{l}(N=3960 \\
\text { Weighted } \\
N=42,133,444)\end{array}$ & & \\
\hline Fair/Poor & 4872 & 20.3 & 4157 & 21.6 & 715 & 14.9 & \\
\hline \multicolumn{8}{|l|}{ Chronic Conditions } \\
\hline Hypertension & 10,207 & 47.4 & 8350 & 48.1 & 1857 & 44.4 & 0.001 \\
\hline Hyperlipidemia & 7732 & 37.8 & 6359 & 38.6 & 1373 & 34.5 & 0.0001 \\
\hline Mood Disorders & 3902 & 20.4 & 3259 & 21.3 & 643 & 17.05 & $<.0001$ \\
\hline Diabetes Mellitus & 4474 & 19.1 & 3673 & 19.4 & 801 & 17.9 & 0.06 \\
\hline Anxiety Disorders & 3589 & 19.4 & 2976 & 19.9 & 613 & 17.1 & 0.002 \\
\hline $\begin{array}{l}\text { Upper Respiratory } \\
\text { Conditions }\end{array}$ & 7405 & 38.8 & 5888 & 38.03 & 1517 & 42.1 & 0.0005 \\
\hline Arthritis & 9250 & 44.9 & 7682 & 46.3 & 1568 & 39.3 & $<.0001$ \\
\hline Asthma & 2557 & 12.2 & 2071 & 12.3 & 486 & 11.8 & 0.4 \\
\hline Coronary Artery Disease & 2197 & 10.8 & 1787 & 11.05 & 410 & 9.8 & 0.04 \\
\hline
\end{tabular}

PCMH indicates Patient-Centered Medical Home

ambulatory and emergency department visits, inpatient stays, and number of prescribed medications were much higher among individuals who suffered from two or more chronic conditions compared to those with no chronic condition [34].

To better understand the characteristics and drivers of that observed trend in this population, we analyzed many factors and found several factors were associated with access to PCMH. A change in one of these factors can cause a change in the PCMH trend. The older adults (66 and older) were less likely than comparable younger adults [19 to 40] to have access to PCMH care. This finding is consistent with what has been reported by prior studies that older patients were less likely to have PCMH access [35]. This can be explained by the dynamic health status of such individuals who often use more than one healthcare provider with no one provider responsible for all care. Older patients with chronic conditions are usually heterogeneous in terms of number and severity of chronic conditions, health status, and risk of adverse events [36]. Thus, policy leaders should promote access to $\mathrm{PCMH}$ care among older patients with chronic conditions because it may help coordinate their complex medical needs, which would improve quality and health outcomes. This was confirmed in a prospective before-and-after study among seniors receiving a PCMH. That study reported that seniors who experienced $\mathrm{PCMH}$ care made fewer and less costly emergency department visits and had fewer hospitalizations [37].

Our findings also revealed that marital status is an important factor associated with access to PCMH. Being separated had the effect of decreasing the likelihood of having access to $\mathrm{PCMH}$ versus being married. Similar to previously published studies, this study showed that the separated patients were less likely to receive $\mathrm{PCMH}$ care, although the number was not significant [38]. Our findings showed a positive association between a higher level of education and having access to $\mathrm{PCMH}$ care. A possible explanation of this finding is that better-educated individuals typically have a higher impact on changing their economic barriers to have full access to PCMH care [39].

All enabling factors were significantly associated with the probability of having $\mathrm{PCMH}$ access. Individuals with private insurance, employed, and living in a high-income family were found to report better access to $\mathrm{PCMH}$. These findings are consistent with the literature in that access to $\mathrm{PCMH}$ is limited due to financial barriers [40]. Therefore, policy makers and health care providers should pay special attention to these barriers as they may negatively affect health-related outcomes, and the effect is substantial, especially among individuals with chronic diseases. Our findings suggest that expanding health insurance coverage is not an adequate approach to increase access to such care, but policy makers should also 
Table 4 Adjusted odds ratios of having access to PCMH care among adults with chronic conditions, 2010-2015

\begin{tabular}{|c|c|c|c|c|c|c|}
\hline \multirow[t]{2}{*}{ Independent Variable } & \multicolumn{2}{|c|}{ Has a PCMH } & \multirow[t]{2}{*}{$O R^{\mathrm{b}}$} & \multicolumn{2}{|c|}{$95 \% \mathrm{Cl}$} & \multirow[t]{2}{*}{$P$} \\
\hline & No & Yes & & & & \\
\hline Predisposing & $N$ & $N$ & & & & \\
\hline \multicolumn{7}{|l|}{ Age (Years) } \\
\hline 19 to 40 & 4299 & 1124 & 1.00 & & & \\
\hline 41 to 65 & 8213 & 2014 & 0.93 & 0.82 & 1.06 & 0.3 \\
\hline 66 and older & 3931 & 822 & 0.80 & 0.67 & 0.95 & 0.01 \\
\hline \multicolumn{7}{|l|}{ Sex } \\
\hline Female & 9926 & 2270 & 1.00 & & & \\
\hline Male & 6517 & 1690 & 1.08 & 0.99 & 1.18 & 0.05 \\
\hline \multicolumn{7}{|l|}{ Race } \\
\hline Non-white & 5485 & 1349 & 1.00 & & & \\
\hline White & 10,958 & 2611 & 1.003 & 0.88 & 1.13 & 0.9 \\
\hline \multicolumn{7}{|l|}{ Marital Status } \\
\hline Married & 8508 & 2302 & 1.00 & & & \\
\hline Never Married & 3465 & 807 & 0.87 & 0.75 & 1.01 & 0.06 \\
\hline Separated & 4470 & 851 & 0.78 & 0.67 & 0.91 & 0.001 \\
\hline \multicolumn{7}{|l|}{ Education Years } \\
\hline$<12$ Years & 2980 & 525 & 1.00 & & & \\
\hline 12 Years & 3833 & 931 & 1.17 & 0.99 & 1.37 & 0.05 \\
\hline$>12$ Years & 6956 & 1920 & 1.25 & 1.05 & 1.48 & 0.01 \\
\hline \multicolumn{7}{|l|}{ Enabling } \\
\hline \multicolumn{7}{|l|}{ Health Insurance } \\
\hline Any Private & 9708 & 2714 & 1.00 & & & \\
\hline Public Only & 5319 & 982 & 0.71 & 0.63 & 0.81 & $<.0001$ \\
\hline Uninsured & 1416 & 264 & 0.73 & 0.59 & 0.91 & 0.005 \\
\hline \multicolumn{7}{|l|}{ Employment Status } \\
\hline Employed & 8656 & 2350 & 1.00 & & & \\
\hline Not employed & 7734 & 1602 & 0.83 & 0.74 & 0.93 & 0.001 \\
\hline \multicolumn{7}{|c|}{ Family Income Categorical } \\
\hline High & 5001 & 1514 & 1.00 & & & \\
\hline Middle & 4747 & 1166 & 0.89 & 0.77 & 1.03 & 0.1 \\
\hline Poor/ Low & 6695 & 1280 & 0.67 & 0.57 & 0.78 & $<.0001$ \\
\hline \multicolumn{7}{|l|}{ Census Region } \\
\hline Midwest & 3175 & 898 & 1.00 & & & \\
\hline Northeast & 2538 & 817 & 1.11 & 0.89 & 1.39 & 0.3 \\
\hline South & 6583 & 1289 & 0.64 & 0.52 & 0.78 & $<.0001$ \\
\hline West & 4147 & 956 & 0.76 & 0.61 & 0.96 & 0.02 \\
\hline \multicolumn{7}{|l|}{ Healthcare Need } \\
\hline \multicolumn{7}{|l|}{ Self-Reported Health } \\
\hline Excellent/Good & 1,1957 & 3187 & 1.00 & & & \\
\hline Fair/Poor & 4157 & 715 & 0.65 & 0.56 & 0.76 & $<.0001$ \\
\hline
\end{tabular}


Table 4 Adjusted odds ratios of having access to PCMH care among adults with chronic conditions, 2010-2015 a (Continued)

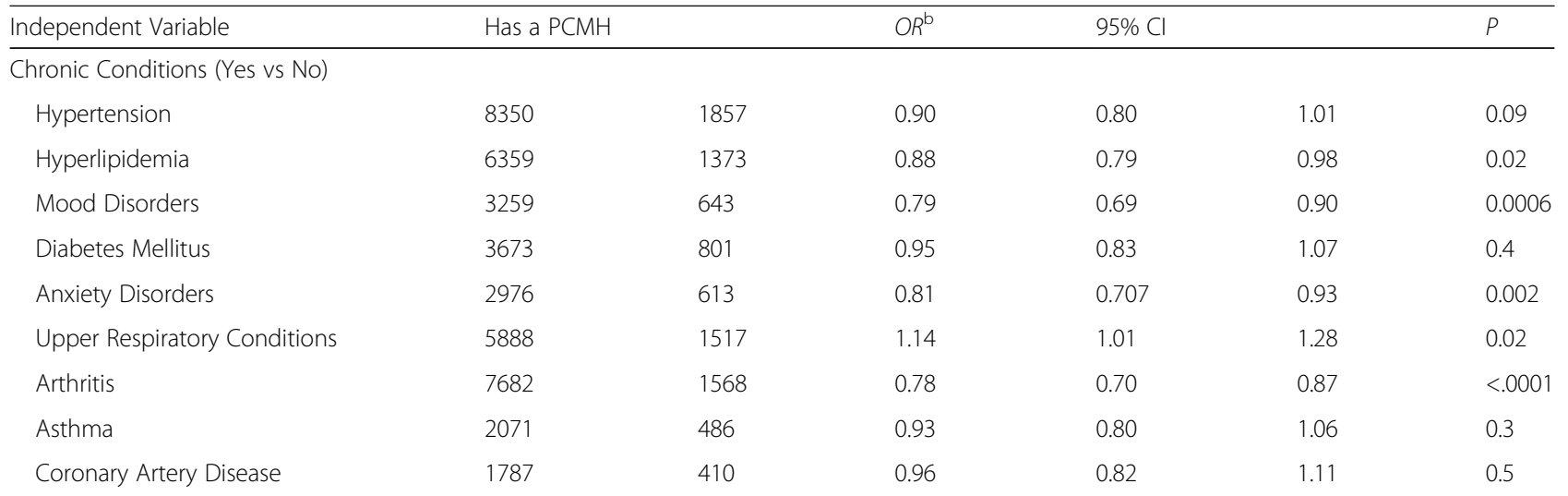

Abbreviations: PCMH indicates Patient-Centered Medical Home; $\mathrm{Cl}$, confidence interval

${ }^{a}$ Sample size $(N)$ is unweighted; Percentage weighted using weights provided with 2010-2015 MEPS

${ }^{\mathrm{b}}$ Adjusted Odds Ratio

improve the provided public health insurance coverage for this population to have better access to PCMH care [41].

Clearly, census region is also important. Individuals who resided in the South or the West were less likely to have access to PCMH. This is not surprising because of the considerable difference in socioeconomic status of the majority of people who live in the South or the West compared to those in other regions. For example, a higher proportion of the population in the South and the West are racially Hispanic and Black [42]. There is evidence in many studies that these groups tend to not seek care for their chronic conditions [43-46]. Furthermore, compared to those in other regions, people in the South or the West are more likely to be uninsured, hence, less likely to have access to PCMH [47].

By looking closely at the chronic conditions, we identified a lack of uniform access to $\mathrm{PCMH}$ care across chronic conditions. We found that hyperlipidemia, mood disorders, anxiety disorders, and arthritis were significantly associated with limited access to $\mathrm{PCMH}$, yet patients with upper respiratory conditions had better access to the care. A possible explanation is that upper respiratory conditions are minor and very common [48, 49]; thus, patients often seek the primary care provider's help instead of the emergency department's help, which results in a lower cost in managing their conditions.

Despite the uniqueness of the information provided by MEPS on individuals' socioeconomics, access to care, and others in the U.S., there are limitations to the interpretation of the results of this study. First, as noted above, MEPS data provide information on the civilian, noninstitutionalized population, and hence exclude individuals living in institutions, such as individuals in nursing homes and long-term care hospitals who live with broad arrays of chronic conditions. Second, the definition of $\mathrm{PCMH}$ used in this study was based on patient responses, which might be subject to recall bias; thus, our estimates may underrepresent actual $\mathrm{PCMH}$ use. Despite the limitations, this study provides an important overview of the access to $\mathrm{PCMH}$ in a nationally representative general population sample of the U.S.

More effort is needed to facilitate access to $\mathrm{PCMH}$ among those with chronic conditions. In the PCMH care model, the primary care health professionals provide labor-intensive work behind the scenes, and it should be compensated accordingly because the total PCMH care fees ultimately demanded by physicians exceed the avoided expense for chronic conditions. This will increase access to $\mathrm{PCMH}$, improve the quality of care, and reduce the overall cost associated with chronic conditions considerably $[50,51]$.

\section{Conclusion}

Despite general agreement about the importance of $\mathrm{PCMH}$, our findings showed strong deficiencies in access to PCMH between 2010 and 2015 to be potentially driven by many factors. These findings serve as a sign for more general problems with access to appropriate care. Moreover, reduced access to comprehensive and continuous services such as PCMH care may exacerbate chronic conditions, leading to more emergency department visits and hospitalizations that might have been preventable, as was reported in the literature. Thus, more resources and efforts need to be devoted to reduce barriers to PCMH care across the U.S., which may 


\section{Appendix}

Table $\mathbf{5}$ Demographic data by state

\begin{tabular}{|c|c|c|c|c|c|c|c|c|c|}
\hline & \multirow{3}{*}{$\begin{array}{l}2017 \\
\text { Population }\end{array}$} & \multicolumn{2}{|l|}{ Sex } & \multicolumn{6}{|l|}{ Race } \\
\hline & & \multirow[t]{2}{*}{ Male } & \multirow[t]{2}{*}{ Female } & \multicolumn{3}{|l|}{ Hispanic } & \multicolumn{3}{|l|}{ Not Hispanic } \\
\hline & & & & White & $\begin{array}{l}\text { Black or African } \\
\text { American }\end{array}$ & Asian & White & $\begin{array}{l}\text { Black or African } \\
\text { American }\end{array}$ & Asian \\
\hline United States & $325,719,178$ & $160,408,119$ & $165,311,059$ & $53,403,379$ & 3673,214 & $1,081,490$ & $203,948,942$ & $43,738,256$ & $21,101,628$ \\
\hline $\begin{array}{l}\text { Northeast } \\
\text { Region }\end{array}$ & $56,470,581$ & $27,530,306$ & $28,940,275$ & $6,670,850$ & $1,413,848$ & 130,784 & $37,714,017$ & $6,915,133$ & $4,206,459$ \\
\hline Connecticut & $3,588,184$ & $1,751,800$ & $1,836,384$ & 494,988 & 79,472 & 7401 & $2,459,296$ & 399,168 & 190,313 \\
\hline Maine & $1,335,907$ & 654,520 & 681,387 & 19,619 & 1833 & 672 & $1,267,954$ & 27,024 & 22,099 \\
\hline Massachusetts & $6,859,819$ & $3,330,365$ & $3,529,454$ & 663,031 & 147,199 & 12,577 & $5,064,022$ & 550,067 & 515,303 \\
\hline New Hampshire & $1,342,795$ & 665,009 & 677,786 & 43,686 & 5339 & 1011 & $1,235,192$ & 24,697 & 43,679 \\
\hline Rhode Island & $1,059,639$ & 514,991 & 544,648 & 129,144 & 30,302 & 2578 & 787,314 & 75,632 & 43,896 \\
\hline Vermont & 623,657 & 308,256 & 315,401 & 10,773 & 1080 & 315 & 590,084 & 11,433 & 14,181 \\
\hline New Jersey & $9,005,644$ & $4,396,574$ & $4,609,070$ & $1,583,995$ & 232,080 & 26,086 & $5,074,996$ & $1,231,086$ & 952,219 \\
\hline New York & $19,849,399$ & $9,637,462$ & $10,211,937$ & $2,972,074$ & 744,422 & 63,004 & $11,249,519$ & $3,080,220$ & $1,914,601$ \\
\hline Pennsylvania & $12,805,537$ & $6,271,329$ & $6,534,208$ & 753,540 & 172,121 & 17,140 & $9,985,640$ & $1,515,806$ & 510,168 \\
\hline Midwest Region & $68,179,351$ & $33,659,324$ & $34,520,027$ & $4,907,673$ & 328,391 & 75,567 & $52,871,947$ & $7,828,966$ & $2,621,209$ \\
\hline Illinois & $12,802,023$ & $6,292,478$ & $6,509,545$ & $2,059,344$ & 92,288 & 26,288 & $8,033,680$ & $1,907,543$ & 792,728 \\
\hline Indiana & $6,666,818$ & $3,287,095$ & $3,379,723$ & 424,866 & 31,395 & 6099 & $5,394,727$ & 699,635 & 182,314 \\
\hline Michigan & $9,962,311$ & $4,903,752$ & $5,058,559$ & 448,997 & 45,859 & 7872 & $7,688,615$ & $1,490,926$ & 373,137 \\
\hline Ohio & $11,658,609$ & $5,713,100$ & $5,945,509$ & 380,535 & 56,605 & 7623 & $9,443,607$ & $1,616,217$ & 319,890 \\
\hline Wisconsin & $5,795,483$ & $2,882,738$ & $2,912,745$ & 360,587 & 25,733 & 5206 & $4,803,844$ & 417,245 & 190,977 \\
\hline lowa & $3,145,711$ & $1,564,733$ & $1,580,978$ & 174,674 & 8476 & 2622 & $2,745,459$ & 143,876 & 94,566 \\
\hline Kansas & $2,913,123$ & $1,451,956$ & $1,461,167$ & 320,506 & 16,978 & 4476 & $2,278,889$ & 204,687 & 105,079 \\
\hline Minnesota & $5,576,606$ & $2,776,846$ & $2,799,760$ & 266,704 & 20,460 & 6451 & $4,570,571$ & 414,490 & 318,572 \\
\hline Missouri & $6,113,532$ & $3,002,236$ & $3,111,296$ & 232,440 & 19,122 & 4914 & $4,977,790$ & 774,014 & 154,207 \\
\hline Nebraska & 1920,076 & 958,131 & 961,945 & 189,923 & 8429 & 2832 & $1,549,724$ & 109,839 & 58,318 \\
\hline North Dakota & 755,393 & 387,299 & 368,094 & 23,519 & 1594 & 574 & 652,943 & 27,037 & 15,402 \\
\hline South Dakota & 869,666 & 438,960 & 430,706 & 25,578 & 1452 & 610 & 732,098 & 23,457 & 16,019 \\
\hline South Region & $123,658,624$ & $60,616,528$ & $63,042,096$ & $20,466,319$ & $1,205,243$ & 240,734 & $72,437,426$ & $24,796,491$ & $5,027,316$ \\
\hline Delaware & 961,939 & 465,514 & 496,425 & 74,221 & 12,835 & 1245 & 617,848 & 223,603 & 44,712 \\
\hline $\begin{array}{l}\text { District of } \\
\text { Columbia }\end{array}$ & 693,972 & 329,199 & 364,773 & 60,912 & 13,196 & 1737 & 267,319 & 325,427 & 35,717 \\
\hline Florida & $20,984,400$ & $10,256,819$ & $10,727,581$ & $4,998,757$ & 346,858 & 46,802 & $11,635,713$ & $3,457,022$ & 716,287 \\
\hline Georgia & $10,429,379$ & $5,075,507$ & $5,353,872$ & 862,177 & 113,757 & 15,801 & $5,667,431$ & $3,381,501$ & 488,821 \\
\hline Maryland & $6,052,177$ & $2,934,154$ & $3,118,023$ & 514,832 & 81,314 & 13,744 & $3,199,793$ & $1,884,099$ & 454,595 \\
\hline North Carolina & $10,273,419$ & 5001,438 & $5,271,981$ & 821,416 & 104,603 & 17,794 & $6,654,534$ & $2,311,221$ & 353,769 \\
\hline South Carolina & $5,024,369$ & $2,437,687$ & $2,586,682$ & 245,815 & 31,699 & 4933 & $3,277,257$ & $1,397,097$ & 103,733 \\
\hline Virginia & $8,470,020$ & $4,166,727$ & $4,303,293$ & 692,903 & 79,560 & 19,440 & $5,438,214$ & $1,730,600$ & 659,457 \\
\hline West Virginia & $1,815,857$ & 898,620 & 917,237 & 26,126 & 2588 & 609 & $1,703,491$ & 80,375 & 19,632 \\
\hline Alabama & $4,874,747$ & $2,359,836$ & $2,514,911$ & 183,434 & 18,971 & 3211 & $3,264,132$ & $1,329,710$ & 86,055 \\
\hline Kentucky & $4,454,189$ & $2,194,318$ & $2,259,871$ & 145,839 & 13,639 & 2959 & $3,844,055$ & 410,166 & 83,722 \\
\hline Mississippi & $2,984,100$ & $1,445,878$ & $1,538,222$ & 78,571 & 12,356 & 1799 & $1,721,204$ & $1,136,985$ & 39,692 \\
\hline Tennessee & $6,715,984$ & $3,275,966$ & $3,440,018$ & 324,771 & 28,280 & 6655 & $5,070,645$ & $1,189,264$ & 148,743 \\
\hline Arkansas & $3,004,279$ & $1,476,064$ & $1,528,215$ & 209,703 & 9559 & 2977 & $2,230,512$ & 487,523 & 58,286 \\
\hline
\end{tabular}


Table 5 Demographic data by state (Continued)

\begin{tabular}{|c|c|c|c|c|c|c|c|c|c|}
\hline & \multirow{3}{*}{$\begin{array}{l}2017 \\
\text { Population }\end{array}$} & \multicolumn{2}{|l|}{ Sex } & \multicolumn{6}{|l|}{ Race } \\
\hline & & \multirow[t]{2}{*}{ Male } & \multirow[t]{2}{*}{ Female } & \multicolumn{3}{|l|}{ Hispanic } & \multicolumn{3}{|c|}{ Not Hispanic } \\
\hline & & & & White & $\begin{array}{l}\text { Black or African } \\
\text { American }\end{array}$ & Asian & White & $\begin{array}{l}\text { Black or African } \\
\text { American }\end{array}$ & Asian \\
\hline Louisiana & $4,684,333$ & $2,289,446$ & $2,394,887$ & 211,356 & 27,336 & 4703 & $2,807,713$ & $1,545,237$ & 101,469 \\
\hline Oklahoma & $3,930,864$ & $1,947,562$ & $1,983,302$ & 360,519 & 20,791 & 5623 & $2,782,296$ & 349,881 & 111,591 \\
\hline Texas & $28,304,596$ & $14,061,793$ & $14,242,803$ & $10,654,967$ & 287,901 & 90,702 & $12,255,269$ & $3,556,780$ & $1,521,035$ \\
\hline West Region & $77,410,622$ & $38,601,961$ & $38,808,661$ & $21,358,537$ & 725,732 & 634,405 & $40,925,552$ & $4,197,666$ & $9,246,644$ \\
\hline Arizona & $7,016,270$ & $3,488,301$ & $3,527,969$ & $2,030,058$ & 68,296 & 35,498 & $3,976,031$ & 360,278 & 284,344 \\
\hline Colorado & $5,607,154$ & $2,822,333$ & $2,784,821$ & $1,107,360$ & 43,409 & 19,603 & $3,944,067$ & 273,910 & 230,929 \\
\hline Idaho & $1,716,943$ & 860,458 & 856,485 & 198,805 & 4338 & 3542 & $1,441,202$ & 19,658 & 37,789 \\
\hline Montana & $1,050,493$ & 528,956 & 521,537 & 32,730 & 1333 & 995 & 930,784 & 10,369 & 13,960 \\
\hline Nevada & 2,998,039 & $1,503,749$ & $1,494,290$ & 791,040 & 38,478 & 24,854 & $1,556,233$ & 304,546 & 303,310 \\
\hline New Mexico & $2,088,070$ & $1,034,144$ & $1,053,926$ & 952,789 & 20,820 & 9381 & 811,077 & 48,485 & 41,353 \\
\hline Utah & $3,101,833$ & $1,561,688$ & $1,540,145$ & 399,778 & 13,416 & 7644 & $2,494,166$ & 50,068 & 103,551 \\
\hline Wyoming & 579,315 & 295,438 & 283,877 & 52,917 & 1579 & 795 & 496,212 & 9466 & 8176 \\
\hline Alaska & 739,795 & 386,792 & 353,003 & 41,519 & 4643 & 2596 & 493,807 & 34,833 & 60,211 \\
\hline California & $39,536,653$ & $19,647,553$ & $19,889,100$ & $14,316,549$ & 459,987 & 416,190 & $15,638,899$ & $2,551,034$ & $6,388,282$ \\
\hline Hawaii & $1,427,538$ & 716,087 & 711,451 & 101,593 & 8043 & 68,273 & 516,294 & 42,935 & 747,347 \\
\hline Oregon & $4,142,776$ & $2,052,989$ & $2,089,787$ & 492,326 & 17,686 & 12,830 & $3,264,775$ & 113,156 & 240,501 \\
\hline Washington & 7405,743 & $3,703,473$ & $3,702,270$ & 841,073 & 43,704 & 32,204 & $5,362,005$ & 378,928 & 786,891 \\
\hline
\end{tabular}

improve the overall health of Americans with chronic conditions.

\section{Acknowledgments}

The authors would like to thank the Saudi Association for Scientific Research (SASR) for providing logistical support throughout the duration of the project.

\section{Funding}

This research did not receive any specific grant from funding agencies in the public, commercial, or not-for-profit sectors.

\section{Availability of data and materials}

The datasets generated and/or analyzed during the current study are available in the AHRQ RDC, [https://meps.ahrq.gov/mepsweb/data_stats/ onsite_datacenter.jsp].

\section{Authors' contributions}

ZA carried out the literature review, statistical analyses, manuscript drafting, manuscript editing, and manuscript revision. NK and IA carried out the study design, statistical analyses, and manuscript revision. RA and AM participated in data collection, statistical analyses, and manuscript editing. NA and TA participated in manuscript editing and manuscript revision. EA and SA participated in study design and data collection, manuscript editing, manuscript revision, and coordination. All authors read and approved the final manuscript.

\section{Ethics approval and consent to participate}

Not applicable.

\section{Consent for publication}

Not applicable.

\section{Competing interests}

The authors declare that they have no competing interests.

\section{Publisher's Note}

Springer Nature remains neutral with regard to jurisdictional claims in published maps and institutional affiliations.

\section{Author details}

${ }^{1}$ Department of Clinical Pharmacy, College of Pharmacy, Prince Sattam Bin Abdulaziz University, Al-Kharj, Riyadh, Saudi Arabia. ${ }^{2}$ Department of Clinical Pharmacy, College of Pharmacy, Umm Al-Qura University, Makkah, Saudi Arabia. ${ }^{3}$ College of Pharmacy, Princess Nourah bint Abdulrahman University, Riyadh, Saudi Arabia. ${ }^{4}$ Department of Pharmaceutical Science, College of Pharmacy, Umm Al-Qura University, Makkah, Saudi Arabia. ${ }^{5}$ Department of Clinical Pharmacy, College of Pharmacy, Jazan University, Jazan, Saudi Arabia. ${ }^{6}$ Department of Pharmaceutics, College of Pharmacy, Prince Sattam Bin Abdulaziz University, Al-Kharj, Riyadh, Saudi Arabia. ${ }^{7}$ College of Pharmacy, Prince Sattam Bin Abdulaziz University, Al-Kharj, Riyadh, Saudi Arabia.

Received: 4 May 2018 Accepted: 21 September 2018

Published online: 27 September 2018

\section{References}

1. Kochanek KD, Murphy SL, Xu JQ, Tejada-Vera B. Deaths: Final data for 2014. National vital statistics reports; vol 65 no 4. Hyattsville, MD: National Center for Health Statistics. 2016. (accessed Feb 16, 2018).

2. United Health Foundation. America's Health Rankings. A call to action for individuals and their communities. 2012 edition. https://assets. americashealthrankings.org/app/uploads/ahr16-complete-v2.pdf. (accessed Feb 16, 2018)

3. Rudegeair P. Americans living longer, with unhealthy lifestyles: Report. Reuters. Dec 11, 2012. http://www.reuters.com/article/ 2012/ 12/11/us-usa-health-rankings-idUSBRE8BA1D220121211. (accessed Feb 16, 2018)

4. Centers for Medicare and Medicaid Services. Chronic conditions among Medicare beneficiaries, chartbook, 2012 edition. Baltimore. 2012. https:// www.cms.gov/Research-Statistics-Data-and-Systems/Statistics-Trends-andReports/Chronic-Conditions/Downloads/2012Chartbook.pdf (accessed Feb 16, 2018). 
5. Ward BW, Schiller JS. Prevalence of multiple chronic conditions among US adults: estimates from the National Health Interview Survey, 2010. Prev Chronic Dis. 2013;10:E65.

6. Centers for Disease Control and Prevention. Leading causes of death and numbers of deaths, by sex, race, and Hispanic origin: United States, 1980 and 2014 (Table 19). Health, United States, 2015. https://www.cdc.gov/nchs/ data/hus/hus15.pdf. (accessed Feb 16, 2018).

7. Facts F. National Center for Chronic Disease Prevention and Health Promotion. CDC. https://www.cdc.gov/chronicdisease/about/costs/. (accessed Feb 16, 2018).

8. Freid VM, Bernstein AB, Bush MA. Multiple chronic conditions among adults aged 45 and over: trends over the past 10 years. NCHS data brief, no. 100. National Center for Health Statistics: Hyattsville, MD; 2012.

9. Chin MH. Improving care and outcomes of uninsured persons with chronic disease. Now. Ann Intern Med. 2008;149(3):206

10. Rittenhouse DR, Shortell SM, Fisher ES. Primary care and accountable care two essential elements of delivery-system reform. N Engl J Med. 2009; 361(24):2301-3.

11. Braddock, C.H., 3rd, et al., The patient-centered medical home: an ethical analysis of principles and practice. J Gen Intern Med, 2013. 28(1): p. 141-146.

12. Rich EC, et al. Organizing Care for Complex Patients in the patient-centered medical home. Ann Fam Med. 2012;10(1):60-2.

13. Palfrey, Judith $\mathrm{S}$., et al. The pediatric Alliance for coordinated care: evaluation of a medical home model. Pediatrics, (2004);113:Supplement 4 1507-1516.

14. Mainous AG, et al. Impact of providing a medical home to the uninsured: evaluation of a statewide program. J Health Care Poor Underserved. 2005; 16(3):515-35.

15. Cleave V. Jeanne, et al. medical homes for children with special health care needs: primary care or subspecialty service? Acad Pediatr. 2016; 16(4):366-72.

16. Cooley WC, et al. Improved outcomes associated with medical home implementation in pediatric primary care. Pediatrics. 2009;124(1):358-64.

17. Rankin KM, et al. Illinois medical home project: pilot intervention and evaluation. Am J Med Qual. 2009;24(4):302-9.

18. Roby $\mathrm{DH}$, et al. Impact of patient-centered medical home assignment on emergency room visits among uninsured patients in a county health system. Med Care Res Rev. 2010;67(4):412-30.

19. Reid RJ, Fishman PA, Yu O, Ross TR, Tufano JT, Michael P. Patient-Centered Medical Home Demonstration: A prospective, quasi-experimental, before and after evaluation. Am J Manag Care. 2009;159:e71-87.

20. Jaén CR. Patient outcomes at 26 months in the patient-centered medical home National Demonstration Project. Ann Fam Med. 2010;8(Suppl 1):S57-67.

21. Ezzati-Rice T, Rohde F, Greenblatt J. Sample design of the medical expenditure panel survey household component, 1998-2007. Methodol Rep. 2008;22.

22. Basu J, Avila R, Ricciardi R. Hospital readmission rates in U.S. states: are readmissions higher where more patients with multiple chronic conditions cluster? Health Serv Res. 2016;51(3):1135-51.

23. Gerteis, J., D. Izrael, D. Deitz, L. LeRoy, R. Ricciardi, T. Miller, and J. Basu, Multiple chronic conditions Chartbook, AHRQ publications no. Q14-0038, Rockville, Md:: Agency for Healthcare Research and Quality, 2014.

24. Medical Expenditure Panel Survey. MEPS HC-036: 1996-2008 Pooled estimation file. Agency for Healthcare Research and Quality, Rockville, MD. Available at: http://www.meps.ahrq.gov/mepsweb/data_stats/download_ data/pufs/h36/h36u08doc.shtml\#30Survey. (accessed Feb 16, 2018),

25. Agency for Healthcare Research and Quality. Defining the PCMH. http:// pcmh.ahrq.gov/page/defining-pcmh. (accessed Feb 16, 2018).

26. Jones AL, Cochran SD, Leibowitz A, et al. Usual primary care provider characteristics of a patient-centered medical home and mental health service use. J Gen Intern Med. 2015. https://doi.org/10.1007/s11606-015-3417-0.

27. Beal A, Hernandez S, Doty M. Latino access to the patient-centered medical home. J Gen Intern Med. 2009;24(Suppl 3):514-20.

28. Jerant A, Fenton JJ, Franks P. Primary care attributes and mortality: a national person-level study. Ann Fam Med. 2012;10(1):34-41.

29. Stockbridge EL, Philpot LM, Pagán JA. Patient-centered medical home features and expenditures by Medicare beneficiaries. Am J Manag Care. 2014;20(5):379-85.

30. Andersen RM. Revisiting the behavioral model and access to medical care: does it matter? J Health Soc Behav. 1995;36(1):10.
31. US Census Bureau: Census Interactive Population Search, 2010. Available at: https://factfinder.census.gov/faces/tableservices/jsf/pages/productview. xhtml?pid=PEP_2017_PEPANNRES\&src=pt. (accessed Sept 6, 2018).

32. Sorace J, et al. The complexity of disease combinations in the Medicare population. Population Health Management. 2011;14(4):161-6.

33. Rao JNK, Scott AJ. On simple adjustments to Chi-Square tests with sample survey data. Ann Stat. 1987;15(1):385-97.

34. Machlin SR, Soni A. Health care expenditures for adults with multiple treated chronic conditions: estimates from the medical expenditure panel survey, 2009. Preventive Chronic Diseases. 2013;10:E63.

35. Tarraf W, Jensen G, González HM. Patient centered medical home care among near-old and older race/ethnic minorities in the US: findings from the medical expenditures panel survey. J Immigr Minor Health. 2017;19(6):1271-80.

36. American Geriatrics Society Expert Panel on the Care of Older Adults with Multimorbidity. Patient-centered Care for Older Adults with multiple chronic conditions: a stepwise approach from the American Geriatrics Society. J Am Geriatr Soc. 2012;60(10):1957-68.

37. Fishman PA, et al. Impact on seniors of the patient-centered medical home: evidence from a pilot study. The Gerontologist. 2012;52(5):703-11.

38. Jones $\mathrm{AL}$, et al. Usual primary care provider characteristics of a patientcentered medical home and mental health service use. J Gen Intern Med. 2015;30(12):1828-36.

39. Making Americans Healthier. Social and economic policy as health policy. Health Aff. 2009;28(2):593.

40. Reibling N. The patient-centered medical home: how is it related to quality and equity among the general adult population? Med Care Res Rev. 2016; 73(5):606-23.

41. DeVoe JE, et al. Insurance + access != health care: typology of barriers to health care access for low-income families. Ann Fam Med. 2007;5(6):511-8.

42. Kaiser Family Foundation estimates based on the Census Bureau's March Current Population Survey (CPS: Annual Social and Economic Supplements), 2017

43. Kim G, Ford KL, Chiriboga DA, Sorkin DH. Racial and ethnic disparities in healthcare use, delayed care, and management of diabetes mellitus in older adults in California. J Am Geriatr Soc. 2012;60:2319-25.

44. Brinjikji W, Rabinstein AA, Lanzino G, Cloft HJ. Racial and ethnic disparities in the treatment of unruptured intracranial aneurysms: a study of the Nationwide inpatient sample 2001-2009. Stroke. 2012;43:3200-6.

45. Eapen ZJ, Al-Khatib S, Lopes RD, et al. Are racial/ ethnic gaps in the use of cardiac resynchronization therapy narrowing? An analysis of 107,096 patients from the national cardiovascular data registry's ICD registry. J Am Coll Cardiol 2012;60:1577-1578.

46. Joshi S, Gaynor JJ, Bayers S, et al. Disparities among blacks, Hispanics, and whites in time from starting dialysis to kidney transplant waitlisting. Transplantation 2013;95:309-18.

47. Kaiser Family Foundation analysis of the 2016 National Health Interview Survey. (accessed 17 Feb 2018).

48. Rietveld RP, Bindels PJE, ter Riet G. Antibiotics for Upper Respiratory Tract Infections and Conjunctivitis in Primary Care: Reconsideration of prescription policy is needed. BMJ: British Medical Journal. 2006;333(7563):311-2.

49. Spillman, Nancy Z. Science of Breath. A Practical Guide, vol. 124. New York: Media Source; 1999.

50. Hussey PS, Eibner C, Ridgely MS, et al. Controlling US health care spending -separating promising from unpromising approaches. N Engl J Med. 2009;361:2109-11.

51. Fields D, Leshen E, Patel K. Analysis \& commentary. Driving quality gains and cost savings through adoption of medical homes. Health Aff (Millwood). 2010;29:819-26. 